\title{
HUBUNGAN MOTIVASI DAN PEKERJAAN IBU DENGAN PEMBERIAN MAKANAN PENDAMPING AIR SUSU IBU (MP-ASI) DINI PADA BAYI DI BAWAH USIA 6 BULAN
}

\author{
Pandu Sandika $^{1}$, Nur Afrinis ${ }^{2}$, Emdas Yahya $^{3}$ \\ Prodi S1 Gizi, FIK, Universitas Pahlawan Tuanku Tambusai ${ }^{1,2}$ \\ Prodi S1 Keperawatan, FIK, Universitas Pahlawan Tuanku Tambusai ${ }^{3}$ \\ pandu.sandika12@gmail.com ${ }^{1}$ afrinis.eva@gmail.com ${ }^{2}$
}

\begin{abstract}
Complementary feeding of breastmilk to infants aged less than 6 months can cause health problems such as constipation, diarrhea and allergies. It will have an impact on the nutritional status of the infant. The purpose of this study was to determine the relationship between motivation and mother occupation with complementary feeding of breastmilk to infants under the age of 6 months in Naga Beralih village. This type of research was analytic with cross sectional design. The population of this research was mothers who have infants aged 0-6 months in Naga Beralih village, the working area of Community Health centre Kampar Utara, totaling 41 people. Data collection tools in this study used a questionnaire. Data analysis in this study used univariate and bivariate analysis with chi square. The results showed that most of the respondents have high motivation in giving complementary breastfeeding, most of the respondents work, most of the respondents give complementary foods to infant under the age of 6 months. There was a relationship of motivation with complementary feeding with $p$ value of 0.001 . There was a work relationship with the provision of complementary feeding under the age of 6 months in Naga Beralih village the work area of Community Health centre Kampar Utara in 2020 with a p value of 0.002. For health workers, in order to increase education about the importance of complementary breastfeeding by forming classes for infants and toddlers to provide information and demonstrations, especially regarding the amount of complementary breastfeeding, types of food and timing of complementary feeding.
\end{abstract}

Keywords $\quad$ : Motivation, Occupation, Early Complementary Feeding Of Breastmilk

\begin{abstract}
ABSTRAK
Pemberian Makanan Pendamping Air Susu Ibu (MP-ASI) pada bayi usia kurang dari 6 bulan dapat menyebabkan gangguan kesehatan seperti konstipasi, diare dan alergi yang akan berdampak pada status gizi bayi. Tujuan penelitian ini adalah untuk mengetahui hubungan motivasi dan pekerjaan ibu dengan pemberian Makanan Pendamping Air Susu Ibu (MP-ASI) pada bayi di bawah usia 6 bulan di Desa Naga Beralih. Jenis penelitian ini adalah analitik dengan rancangan cross sectional. Populasi penelitian ini adalah ibu yang memiliki bayi usia 0-6 bulan di Desa Naga Beralih wilayah kerja Puskesmas Kampar Utara yang berjumlah 41 orang dengan teknik pengambilan sampel menggunakan total sampling. Alat pengumpulan data dalam penelitian ini menggunakan kuesioner. Analisa data dalam penelitian ini menggunakan analisa univariat dan bivariat dengan uji chi-square. Hasil penelitian didapatkan bahwa sebagian besar responden memiliki motivasi yang tinggi dalam pemberian MP-ASI Dibawah usia 6 bulan, sebagian besar responden bekerja, sebagian besar responden memberikan MP-ASI dibawah usia 6 bulan pada bayi, terdapat hubungan motivasi dengan pemberian MP-ASI dibawah usia 6 bulan di Desa Naga Beralih Wilayah Kerja Puskesmas Kampar Utara tahun 2020 dengan $\mathrm{p}$ value 0,001, terdapat hubungan pekerjaan dengan pemberian MP-ASI dibawah usia 6 bulan di Desa Naga Beralih Wilayah Kerja Puskesmas Kampar Utara tahun 2020 dengan $\mathrm{p}$ value 0,002. Bagi petugas kesehatan agar dapat meningkatkan penyuluhan tentang pentingnya pemberian MP ASI dengan membentuk kelas bayi dan balita untuk memberikan penyuluhan dan demonstrasi khususnya mengenai jumlah pemberian MP ASI, jenis makanan dan waktu pemberian MP ASI
\end{abstract}

Kata Kunci : Motivasi, Pekerjaan, MP-ASI Dini 


\section{PENDAHULUAN}

Bayi merupakan generasi penerus Sumber Daya Manusia (SDM) dan masa depan untuk melanjutkan pembangunan. Oleh karena itu harus diberikan lingkungan yang kondusif agar mereka dapat tumbuh dan berkembang optimal, sehat, cerdas, dan memiliki karakter sesuai dengan nilai bangsa Indonesia. Salah satu upaya untuk menjamin kualitas tumbuh kembang bayi adalah memberikan makanan terbaik bagi anak sejak lahir hingga usia 2 tahun (Depkes, 2017).

Pola pemberian makanan terbaik bagi bayi dan anak adalah memberikan Air Susu Ibu (ASI) kepada bayi segera dalam waktu 30 menit setelah bayi lahir, memberikan ASI secara ekslusif sejak lahir sampai bayi berusia 6 bulan, memberikan Makanan Pendamping Air Susu Ibu (MP-ASI) sejak bayi berusia 6 bulan sampai 24 bulan, dan meneruskan pemberian ASI sampai anak berusia 24 bulan atau lebih (Anggareni, 2017).

Menurut World Health Organization (WHO) tahun 2017 menunjukkan rata-rata angka pemberian ASI eksklusif di dunia baru berkisar $38 \%$, sedangkan saat ini persentase global pada bayi $0-6$ bulan yang mendapat MP-ASI adalah 62\%. Pemberian MP-ASI dini dapat menyebabkan gangguan kesehatan seperti konstipasi, diare, alergi, muntah, menurunnya frekuensi dan intensitas pengisapan bayi, memperberat kerja pencernaan dan ginjal sehingga berdampak terhadap terjadinya kematian akibat infeksi neonatal 45\%, kematian akibat diare 30\%, dan akibat infeksi pencernaan (ileus obstruksi) 38\%. Jika pemberian MP-ASI terlambat akan sulit mengembangkan keterampilan makan seperti menggigit, mengunyah, tidak menyukai makanan padat dan kekurangan gizi (Sari, 2017).

MP-ASI merupakan makanan atau minuman yang mengandung gizi yang diberikan kepada bayi atau anak untuk memenuhi kebutuhan gizi selain ASI setelah umur 6 bulan. MP-ASI berbentuk lunak, setengah cair atau lembek sesuai dengan kondisi bayi. MP-ASI berguna untuk pertumbuhan dan perkembangan fisik, psikomotor, otak, dan kognitif sikecil (Annisa, 2016).

MP-ASI harus mulai diberikan ketika bayi tidak lagi mendapat cukup energi dan nutrient dari ASI. Untuk kebanyakan bayi, makanan tambahan mulai di berikan pada usia 6 bulan. Pada usia ini otot dan syaraf di dalam mulut bayi cukup berkembang untuk mengunyah. Sebelum usia 4 bulan, bayi akan mendorong makanan keluar dari mulutnya karena mereka belum bisa mengendalikan gerakan lidahnya dengan baik (Ratih, 2017).

Pemberian makanan campuran berarti memberi makan bayi dengan ASI dan makanan atau cairan lain, seperti susu formula, susu hewani, atau air putih Memberikan makanan campuran sebelum bayi berusia 6 bulan dapat merusak pencernaan. Bayi terkena penyakit seperti diare dan pneumonia serta gizi buruk. Ini akan mengurangi perlindungan yang dapat diberikan oleh ASI eksklusif, dan seluruh keuntungan yang bisa didapatkan bayi dari pemberian ASI eksklusif.

Berdasarkan hasil Data Riset Kesehatan Dasar (RISKESDAS) tahun 2018 di Indonesia meskipun sejumlah besar perempuan menyusui anak mereka dalam kehidupan mereka, hanya $42 \%$ dari bayi yang berusia di bawah 6 bulan yang mendapatkan ASI eksklusif dan sebanyak $58 \%$ bayi sudah di perkenalkan dengan makanan tambahan sedangkan target pemberian ASI eksklusif adalah $80 \&$ (Astuti, 2018). Rendahnya pemberian ASI ekslusif disebabkan oleh banyak faktor seperti pengetahuan ibu dan dukungan keluarga (Afrinis, Indrawati, \& Haspriyanti, 2020).

Di Provinsi Riau tahun 2018 pemberian MP-ASI sebelum usia 6 bulan meningkat (54,1\%) dibandingkan dengan tahun 2017 (48\%) (Profil Kesehatan Provinsi Riau, 2018). Persentase untuk bayi yang diberi 
MP-ASI pada tahun 2017 di Kabupaten Kampar adalah 7.039 bayi dari 14.098 bayi (50\%), dan tahun 2018 berjumlah 11.449 (76,9\%) bayi yang diberi MP-ASI dari 14.888 jumlah bayi keseluruhan. Sementara tahun 2019 Kabupaten Kampar memiliki 15.462 bayi. Bayi yang diberi MP-ASI dibawah usia 6 bulan adalah 77,6\% (Dinkes Kampar, 2019). Berdasarkan data yang diperoleh di Dinas Kesehatan Kabupaten Kampar tahun 2019 cakupan pemberian MP-ASI di bawah usia kurang dari 6 Puskesmas Kampar Utara berada pada posisi nomor 2 tertinggi dengan persentase 23,7\%. Berdasarkan data cakupan pemberian MP-ASI pada bulan JanuariMaret tahun 2020 di wilayah kerja Puskesmas Kampar Utara desa Naga Beralih menempati daerah tertinggi pemberian MP-ASI yaitu dibawah usia 6 bulan yaitu sebanyak 23 bayi $(56,1 \%)$.

Ada beberapa faktor yang dapat mempengaruhi ibu dalam pemberian MPASI dini pada bayi, seperti faktor dari ibu sendiri atau faktor dari luar. Faktor dari ibu yaitu pengetahuan ibu, budaya, pendidikan, sikap, motivasi dan ibu yang bekerja diluar rumah sedangkan faktor dari luar seperti promosi susu, formula, promosi kesehatan, fasilitas kesehatan dan sebagainya (Asmarudin, 2017).

Motivasi berperan penting dalam faktor pemberian MP-ASI dini pada bayi. Ibu akan termotivasi untuk memberikan MP-ASI dini kepada bayinya karena ibu akan merasa khawatir bahwa dengan menyusui akan merubah bentuk payudara menjadi jelek, dan takut badan akan menjadi gemuk. Dengan alasan inilah ibu memberikan makanan pendamping ASI dini (Widari 2017).

Ibu yang bekerja kurang mendukung dalam pemberian ASI ekslusif dibandingkan ibu yang tidak bekerja. Hal ini dikarenakan ibu yang tidak melakukan pekerjaan di luar rumah (IRT) akan memiliki banyak waktu dan kesempatan untuk menyusui bayinya dibandingkan dengan ibu yang bekerja di luar rumah. Ibu yang bekerja akan merasa ASI nya tidak mencukupi kebutuhan gizi bayinya sehingga ibu memilih susu formula karena lebih praktis (Lestari, 2013).

Berdasarkan survey pendahuluan yang dilakukan peneliti pada bulan April 2020 di Desa Naga Beralih wilayah kerja Puskesmas Kampar Utara tahun 2020 dengan wawancara terhadap 10 orang ibu yang memiliki bayi 0-6 bulan, dari hasil wawancara diperoleh 7 orang ibu $(70 \%)$ termotivasi untuk memberikan MP-ASI pada bayi sebelum usia 6 bulan ( $100 \%)$, karena takut ASInya tidak cukup dan bayinya kekurangan gizi, sebanyak 6 orang ibu $(60 \%)$ bekerja, sehingga waktu ibu tidak cukup untuk selalu memberikan ASI kepada bayinya dan ibu menganggap bahwa pemberian ASI saja tidak mencukupi untuk kebutuhan bayi dan perlu diberikan makanan tambahan seperti pisang, biskuit, dan nasi tim.

Tujuan penelitian ini adalah untuk mengetahui hubungan motivasi dan pekerjaan ibu dengan pemberian Makanan Pendamping ASI (MP-ASI) pada bayi di bawah usia 6 bulan di Desa Naga Beralih Wilayah Kerja Puskesmas Kampar Utara Tahun 2020.

\section{METODE}

Jenis penelitian ini adalah survei analitik dengan rancangan desain rancangan cross sectional, yaitu rancangan penelitian dengan melakukan pengukuran atau pengamatan variabel independen dan variabel dependen saat bersamaan. Penelitian ini dilaksanakan di Desa Naga Beralih pada tanggal 01 Juni - 07 Juli tahun 2020. Populasi dalam penelitian ini adalah semua ibu yang mempunyai bayi usia 0-6 bulan pada bulan Januari-Maret 2020 yaitu sebanyak 41 orang. Sampel dalam penelitian ini adalah sebagian ibu yang memiliki bayi usia dibawah usia 6 bulan dengan teknik pengambilan sampel menggunakan teknik total sampling yang berjumlah 41 orang.

Analisa data Analisis data dalam penelitian ini menggunakan Analisa 
Univariat dan Analisa Bivariat. Analisa univariat untuk melihat distribusi frekuensi dan persentase dari motivasi ibu, pekerjaan ibu dan pemberian MP-ASI dini. Analisa bivariat menggunakan uji Chi-Square $\left(\mathrm{X}^{2}\right)$ dengan menggunakan tingkat kepercayaan $95 \%$.

\section{HASIL}

Penelitian ini dilakukan di desa Naga Beralih wilayah kerja Puskesmas Kampar Utara pada $41 \mathrm{ibu}$ yang memiliki bayi usia 0 - 6 bulan. Hasil penelitian tersebut dapat disajikan sebagai berikut:

\section{Karakteristik Responden}

Karakteristik responden dalam penelitian ini terdiri dari umur ibu dan pendidikan ibu, karakteristik responden dapat dilihat pada tabel berikut:

Tabel 1: Distribusi Frekuensi Umur dan Pendidikan ibu Responden

\begin{tabular}{clcc}
\hline No & Umur Ibu & n & \% \\
\hline 1 & $17-25$ tahun & 18 & 43,9 \\
$\mathbf{2}$ & $\mathbf{2 6 - 3 5}$ tahun & $\mathbf{2 3}$ & $\mathbf{5 6 , 1}$ \\
\hline & & $\mathbf{4 1}$ & $\mathbf{1 0 0}$ \\
\hline & Pendidikan Ibu & & \\
\hline 1 & Rendah (SD, SMP) & 7 & 17,1 \\
$\mathbf{2}$ & Tinggi (SMA, PT) & $\mathbf{3 4}$ & $\mathbf{8 2 , 9}$ \\
\hline & Total & $\mathbf{4 1}$ & $\mathbf{1 0 0}$ \\
\hline
\end{tabular}

Berdasarkan tabel 1 dapat diketahui bahwa dari 41 responden sebanyak $23 \mathrm{ibu}$
$(56,1 \%)$ berumur $26-35$ tahun dan sebanyak $34 \mathrm{ibu}(82,9 \%)$ berpendidikan tinggi.

\section{AnalisaUnivariat}

Analisa univariat dalam penelitian ini terdiri dari motivasi, pekerjaan dan pemberian MP-ASI dini yang dapat dilihat pada table 2 berikut:

Tabel 2: Distribusi Frekuensi Motivasi, Pekerjaan dan Pemberian MP-ASI Dini pada bayi di bawah Usia 6 Bulan

\begin{tabular}{lcc}
\hline \multicolumn{1}{c}{ Motivasi } & $\mathbf{n}$ & $\mathbf{\%}$ \\
\hline Tinggi & 19 & 46,3 \\
Rendah & $\mathbf{2 2}$ & $\mathbf{5 3 , 7}$ \\
\hline \multicolumn{1}{c}{ Pekerjaan } & & \\
\hline Bekerja & $\mathbf{2 6}$ & $\mathbf{6 3 , 4}$ \\
Tidak bekerja & 15 & 36,6 \\
\hline \multicolumn{1}{c}{ MP-ASI Dini } & \\
\hline Ya & $\mathbf{2 5}$ & $\mathbf{6 1}$ \\
Tidak & 16 & 39 \\
\hline \multicolumn{1}{c}{ Jumlah } & $\mathbf{4 1}$ & $\mathbf{1 0 0}$ \\
\hline
\end{tabular}

Berdasarkan tabel 2 dapat diketahui bahwa dari 41 responden sebanyak 22 responden $(53,7 \%)$ memiliki motivasi yang rendah dalam memberikan MP-ASI dini, sebanyak 26 responden $(63,4 \%)$ ibu bekerja dan sebanyak 25 responden $(61 \%)$ memberikan MP-ASI dini kepada bayinya.

\section{Analisa Bivariat}

Analisa bivariat bertujuan untuk melihat hubungan antara variabel motivasi dan pemberian MP-ASI dini pada bayi usia 0-6 bulan. Analisa bivariat dalam penelitian ini adalah sebagai berikut:

Tabel 3 : Hubungan Motivasi dengan Pemberian MP-ASI Dini

\begin{tabular}{lcccccccc}
\hline \multirow{2}{*}{ Motivasi Ibu } & \multicolumn{7}{c}{ Pemberian MP-ASI Dini } \\
\cline { 2 - 10 } & $\mathrm{n}$ & $\%$ & $\mathrm{n}$ & $\%$ & $\mathrm{n}$ & $\%$ & P value & POR \\
\hline Rendah & 19 & 86,4 & 3 & 13,6 & 22 & 100 & & \\
Tinggi & 6 & 31,6 & 13 & 68,4 & 19 & 100 & 0,001 & 13,7 \\
\hline Jumlah & 25 & 61,0 & 16 & 39,0 & 41 & 100 & & \\
\hline
\end{tabular}

Berdasarkan tabel 3 dapat dilihat bahwa dari 22 responden yang memiliki motivasi rendah dalam pemberian MP-ASI dibawah usia 6 bulan terdapat 3 responden $(13,6 \%)$ yang tidak memberikan MP-ASI dibawah usia 6 bulan pada bayi. Sedangkan dari 19 responden yang memiliki motivasi yang tinggi, terdapat 6 responden $(31,6 \%)$ yang memberikan MP-ASI dibawah usia 6 bulan pada bayi. Berdasarkan uji chi square diperoleh nilai $\mathrm{p}$ value $=0,001(\mathrm{p}<0,05)$, ini berarti terdapat hubungan yang signifikan antara motivasi dengan pemberian MP-ASI di bawah usia 6 bulan. 
Berdasarkah hasil penelitian diketahui nilai $\mathrm{POR}=13,7$, hal ini berarti bahwa responden yang memiliki motivasi rendah dalam pemberian MP-ASI pada bayi dibawah usia
6 bulan berisiko 13,7 kali untuk memberikan MP-ASI dibawah usia 6 bulan pada bayi dibandingkan dengan responden yang memiliki motivasi tinggi.

\section{Tabel 4: Hubungan Pekerjaan dengan Pemberian MP-ASI Dini}

Pekerjaan

\section{Pemberian MP-ASI Dini}

\begin{tabular}{lcccccccc} 
& \multicolumn{3}{c}{ Ya } & \multicolumn{2}{c}{ Tidak } & \multicolumn{2}{c}{ P value } & POR \\
& $\mathrm{n}$ & $\%$ & $\mathrm{n}$ & $\%$ & $\mathrm{n}$ & $\%$ & & 11,5 \\
\hline Bekerja & $\mathbf{2 1}$ & $\mathbf{8 0 , 8}$ & $\mathbf{5}$ & $\mathbf{1 9 , 2}$ & $\mathbf{2 6}$ & $\mathbf{1 0 0}$ & \multirow{2}{*}{$\mathbf{0 0 2}$} & \\
Tidak Bekerja & $\mathbf{4}$ & $\mathbf{2 6 , 7}$ & $\mathbf{1 1}$ & $\mathbf{7 3 , 3}$ & $\mathbf{1 5}$ & $\mathbf{1 0 0}$ & & \\
\hline Jumlah & $\mathbf{2 5}$ & $\mathbf{6 1 , 0}$ & $\mathbf{1 6}$ & $\mathbf{3 9 , 0}$ & $\mathbf{4 1}$ & $\mathbf{1 0 0}$ & &
\end{tabular}

Berdasarkan tabel 4 dapat dilihat bahwa dari 26 responden yang bekerja terdapat 5 responden $(19,2 \%)$ yang tidak memberikan MP-ASI dibawah usia 6 bulan pada bayi, sedangkan dari 21 responden yang tidak bekerja terdapat 4 responden $(26,7 \%)$ yang memberikan MP-ASI dibawah usia 6 bulan pada bayi. Berdasarkan uji chi-square diperoleh nilai $p$ value $=0,002(p<0,05)$, dengan derajat kemaknaan $(\alpha=0,05)$. Ini berarti terdapat hubungan yang signifikan antara pekerjaan dengan pemberian MP-ASI di bawah usia 6 bulan. Berdasarkah hasil penelitian juga diketahui nilai $P O R=11,5$ hal ini berarti responden yang bekerja berisiko 11,5 kali untuk memberikan MP-ASI dibawah usia 6 bulan pada bayi dibandingkan dengan responden yang tidak bekerja.

\section{PEMBAHASAN}

\section{Hubungan Motivasi dengan Pemberian MP-ASI Dibawah Usia 6 Bulan}

Berdasarkan hasil penelitian dapat dilihat bahwa dari 22 responden yang yang memiliki motivasi rendah dalam pemberian MP-ASI dibawah usia 6 bulan terdapat 3 responden $(13,6 \%)$ yang tidak memberikan MP-ASI dibawah usia 6 bulan pada bayi , sedangkan dari 19 responden yang memiliki motivasi tinggi dalam pemberian MP-ASI dibawah usia 6 bulan terdapat 6 responden $(31,6 \%)$ yang memberikan MPASI dibawah usia 6 bulan pada bayi. Berdasarkan uji statistik diperoleh nilai $\mathrm{p}$ value $=0,001(\mathrm{p}<0,05)$, dengan derajat kemaknaan $(\alpha=0,05)$. Ini berarti terdapat hubungan yang signifikan antara motivasi dengan pemberian MP-ASI di bawah usia 6 bulan

Menurut asumsi peneliti responden yang memiliki motivasi tinggi dalam pemberian MP-ASI dibawah usia 6 bulan tetapi tidak memberikan MP-ASI kepada anaknya dibawah usia 6 bulan disebabkan karena responden produksi ASInya lancar sehingga mereka tetap memberikan ASI eksklusif pada bayi dan juga dapat menghemat pengeluaran, sedangkan responden yang tidak memiliki motivasi tinggi dalam pemberian MP-ASI dibawah usia 6 bulan tetapi memberikan MP-ASI kepada anaknya dibawah usia 6 bulan disebabkan karena asupan nutrisi ibu yang kurang baik, menu makanan yang tidak seimbang dan juga mengkonsumsi makanan yang kurang teratur sehingga produksi ASI ibu tidak mencukupi untuk bayi dan ibu akan memberikan makanan tambahan pada bayi usia 6 bulan.

Motivasi berperan penting dalam faktor pemberian MP-ASI dini pada bayi. Ibu akan termotivasi untuk memberikan MP-ASI dini kepada bayinya karena ibu akan merasa khawatir bahwa dengan menyusui akan merubah bentuk payudara menjadi jelek, dan takut badan akan menjadi gemuk. Dengan alasan inilah ibu memberikan makanan pendamping ASI dini (Widari 2017).

Motivasi adalah suatu usaha yang disadari untuk mempengaruhi tingkah laku 
seseorang agar ia bergerak hatinya untuk bertindak melakukan sesuatu sehingga mencapai hasil dan tujuan tertentu. Motivasi dipengaruhi oleh beberapa faktor yaitu faktor instrinsik dan faktor ekstrinsik, Yang dimaksud dengan motivasi instrinsik adalah motivasi yang berasal dari diri seseorang, sedangkan motivasi ekstrinsik berasal dari luar diri seseorang. Faktor instrinsik adalah pendidikan, pengalaman dan pengetahuan sedangkan faktor ekstrinsik adalah ekonomi, sosial budaya maupun lingkungan (Notoatmodjo, 2010).

Hasil Penelitian sejalan dengan hasil penelitian yang dilakukan oleh Rohmatika (2017) mengenai Pemberian Makanan Pendamping ASI Dini pada Bayi Di Posyandu Karyamulya Jetis Jaten didapatkan ada hubungan motivasi dengan pemberian MP-ASI Dini pada bayi dengan $\mathrm{p}$ value 0,004

\section{Hubungan pekerjaan dengan Pemberian MP-ASI Dibawah Usia 6 bulan}

Dari hasil penelitian diketahui bahwa dari 26 responden yang bekerja terdapat 5 responden $(19,2 \%)$ yang tidak memberikan MP-ASI dibawah usia 6 bulan pada bayi, sedangkan dari 21 responden yang tidak bekerja terdapat 4 responden $(26,7 \%)$ yang memberikan MP-ASI dibawah usia 6 bulan pada bayi. Berdasarkan uji statistik diperoleh nilai $\mathrm{p}$ value $=0,002(\mathrm{p}<0,05)$, dengan derajat kemaknaan $(\alpha=0,05)$. Ini berarti terdapat hubungan yang signifikan antara pekerjaan dengan pemberian MPASI di bawah usia 6 bulan.Berdasarkah hasil penelitian juga diketahui nilai $\mathrm{POR}=11,5$ hal ini berarti responden yang bekerja berisiko 11,5 kali untuk memberikan MP-ASI dibawah usia 6 bulan pada bayi dibandingkan dengan responden yang tidak bekerja.

Menurut asumsi peneliti responden yang bekerja tetapi tidak memberikan MPASI dibawah usia 6 bulan disebabkan karena lokasi atau tempat kerja ibu yang dekat dari lingkungan tempat tinggal yang membuat ibu sempat untuk memberikan
ASI secara eksklusif kepada bayinya. Sedangkan responden yang tidak bekerja tetapi memberikan MP-ASI dibawah usia 6 bulan disebabkan karena kondisi ibu yang selalu dalam keadaan tertekan, sedih, kecemasan, kurang percaya diri sehingga akan menurunkan volume ASI dan ibu akan termotivasi dalam memberikan MP-ASI dibawah usia 6 bulan kepada bayi untuk mencukupi kebutuhan bayi.

Ibu yang hanya bekerja di rumah dan mempunyai banyak waktu di rumah tidak selamanya memberikan MP-ASI tepat pada waktunya, ini terbukti dari hasil penelitian dimana banyak ibu yang bekerja di rumah atau hanya sebagai ibu rumah tangga sudah memberikan makanan tambahan sebelum waktu yang di anjurkan. Banyak ibu yang bekerja di rumah dan bekerja di luar rumah yang mengkombinasikan ASI dengan makanan tambahan seperti bubur instan, walaupun bayi belum layak diberikan MPASI.

Pekerjaan adalah mata pencaharian sehari-hari dari seseorang untuk mencari uang dalam memenuhi kebutuhan seharihari. Pekerjaan berperan besar terhadap seseorang melakukan tindakan pemberian makanan tambahan pendamping ASI. Status pekerjaan ibu merupakan faktor yang bersifat memproteksi, artinya ibu yang tidak bekerja akan lebih mendukung dalam pemberian ASI ekslusif dibandingkan ibu yang bekerja. Hal ini dikarenakan ibu yang tidak melakukan pekerjaan di luar rumah (IRT) akan memiliki banyak waktu dan kesempatan untuk menyusui bayinya dibandingkan dengan ibu yang bekerja di luar rumah. Selain itu masih banyak ibu yang beranggapan salah tentang ASI eksklusif, ibu juga merasa khawatir bahwa dengan menyusui akan merubah bentuk payudara menjadi jelek, dan takut badan akan menjadi gemuk. Dengan alasan inilah ibu memberikan makanan pendamping ASI, karena ibu merasa ASI nya tidak mencukupi kebutuhan gizi bayinya sehingga ibu memilih susu formula karena lebih praktis (Lestari, 2013). 
Sosial ekonomi keluarga secara tidak langsung dapat mempengaruhi ketersediaan pangan dalam keluarga. Adanya ketersediaan pangan dalam keluarga mempengaruhi pola konsumsi yang selanjutnya mempengaruhi pola konsumsi yang selanjutnya berpengaruh terhadap intake gizi keluarga.

Hasil penelitian ini sesuai dengan penelitian Hasanah didapatkan bahwa ada hubungan pekerjaan dengan pemberian MP-ASI Dini pada bayi usia 0-6 bulan di Puskesmas Sidomulyo Pekanbaru dengan $p$ value 0,000 . Hasil penelitian ini juga sesuai dengan penelitian Ratna (2017) menunjukan ada hubungan antara pekerjaan keluarga dengan pemberian MP-ASI pada bayi usia 0-6 bulan di BPM Nurtila Palembang tahun 2016 dengan $p$ value 0,000

\section{KESIMPULAN}

Hasil penelitian tentang hubungan motivasi dan pekerjaan dengan pemberian MP-ASI dibawah usia 6 bulan di Desa Naga Beralih Wilayah Kerja Puskesmas Kampar Utara tahun 2020 diperoleh hasil sebagian besar responden memiliki motivasi yang tinggi dalam pemberian MPASI dini, sebagian besar ibu responden bekerja dan sebagian besar responden memberikan MP-ASI dini kepada bayi dibawah usia 6 bulan.

Terdapat hubungan yang signifikan antara motivasi ibu dengan pemberian MPASI dini pada bayi dibawah usia 6 bulandan terdapat hubungan yang signifikan antara pekerjaan dengan pemberian MP-ASI dini pada bayi dibawah usia 6 bulan di Desa Naga Beralih Wilayah Kerja Puskesmas Kampar Utara tahun 2020.

\section{UCAPAN TERIMAKASIH}

Dalam penelitian ini, peneliti banyak mendapatkan bantuan dari berbagai pihak. Sehubungan dengan hal tersebut peneliti mengucapkan terima kasih kepada dosen
Program Studi S1 Gizi Universitas Pahlawan Tuabku Tambusai, dan Puskesmas Kampar Utara.

\section{DAFTAR PUSTAKA}

Afrinis, N., Indrawati, \& Haspriyanti, N. (2020). Hubungan Pengetahuan Ibu tentang Manajemen Laktasi dan Dukungan Keluarga dengan Pemberian ASI Eksklusif pada Bayi Usia 0-6 Bulan. Prepotip Jurnal Kesehatan Masyarakat, 4(2), 157168.

https://doi.org/10.33024/jkm.v6i2.172 6

Anggareni, D. (2017). Fast Food for Baby. Jakarta Selatan: Mitra Cendikia Press

Annisa. (2016). Pengaruh Faktor Internal dan Eksternal Terhadap Usia Pemberian MP-ASI di Wilayah Kerja Puskesmas Wonomerto Kabupaten Probolinggo. Jurnal Kesehatan

Astuti. (2018). Perbedaan Dukungan Nenek Dalam Keluarga Extended Family Pada Pemberian ASI Eksklusif dan Tidak Eksklusif di Wilayah Kerja Puskesmas Arjasa, Kabupaten Jember. Program Studi Ilmu Keperawatan. Universitas Jember. Jember

Asmarudin. (2017). Faktor - Faktor yang Berhubungan dengan Pemberian MP-ASI pada Bayi Usia 0-6 Bulan di BPM Nurtila Palembang. Jurnal Kesehatan Vol VII No 2 Agustus 2016 hlm 260-265. STIK Siti Khadijah. Palembang

Depkes RI. (2017). Makanan Pendamping ASI. Jakarta: Depertemen Kesehatan

Dinas Kesehatan Kabupaten Kampar. (2019). Cakupan Pemberian ASI Ekslusif Kabupaten Kampar 2019

Lestari. (2013). Hubungan Pengetahuan Dan Sikap Ibu Dengan Pemberian MPASI Di Kelurahan PB. Selayang II Kecamatan Medan 
Selayang Tahun 2011". http://repository.usu.ac.id/handle/

Notoatmodjo, S. (2010). Metodologi Penelitian Kesehatan. Edisi Revisi. Jakarta: Rineka Cipta

Profil Kesehatan Provinsi Riau. (2018). Cakupan ASI Ekslusif Di Provinsi Riau.

Puskesmas Kampar Utara (2020) Cakupan Pemberian ASI ekslusif di Wilayah Kerja Puskesmas Kampar Utara

Ratih. (2017). Hubungan Pengetahuan Dan Sikap Ibu Dengan Pemberian MPASI Di Kelurahan PB. Selayang II Kecamatan Medan Selayang

Rohmatika D. (2012). Hubungan Tingkat Pengetahuan Ibu dengan Pemberian Makanan Pendamping ASI Bayi Umur 6-24 Bulan Di Posyandu Karyamulya Jetis Jaten. Jurnal Kesehatan Kusuma Husada. Vol 3 no 1.

Sari. (2017). Hubungan antara Pengetahuan Ibu dan Faktor-Faktor Sosial Ekonomi Orangtua dengan Praktik Pemberian Makanan Pendamping ASI (MP-ASI pada Bayi Usia 6-12 Bulan di Desa Kemuning Kecamatan Ampelgading Kabupaten Pemalang.

RISKESDAS (2018). Cakupan ASI Ekslusif Di Dunia dan Indonesia.

Widari. (2017). Menyiapkan Makanan Pendampng ASI. Jakarta : Pustaka Swara. 